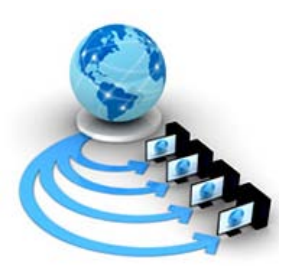

Volume 8, No. 8, September-October 2017

\title{
COMPARATIVE STUDY OF ROUTING PROTOCOLS IN AD-HOC WIRELESS NETWORK
}

\author{
Jayashree Agarkhed \\ Professor, Department of C.S.E, P.D.A College of Engineering, \\ Kalaburagi, India
}

\begin{abstract}
Mobile ad hoc networks (MANETs) are self-configured, dynamic and multi hop networks. Routing means the movement of information from source to destination within the connected network. This paper presents some of the work done on routing protocols for ad-hoc wireless network and focuses on classification of routing protocols. The energy consumption analysis of wireless ad hoc network routing protocols under different energy models, relative performance analysis of proactive routing protocols, analyzing the behavior and performance of opportunistic routing protocols, routing in highly dynamic ad hoc networks.
\end{abstract}

Keywords: Ad hoc network, Routing, MANET

\section{INTRODUCTION}

MANET is a highly flexible network where nodes can freely move and join, with no fixed infrastructure, and thus it is vulnerable to attacks by malicious users. In MANETs, the nodes communicate with each other without any existing infrastructure and go wireless. The major benefits of MANETs are rapid deployment, robustness, flexibility and inherent support for mobility. The mobility of the nodes is random and nodes organize themselves in arbitrarily topology. MANET has various potential applications, such as emergency search-rescue operations, meeting events, conferences, and battlefield communication between moving vehicles and/or soldiers. The wireless nature of Mobile Ad hoc network needs address issues and challenges. They can multi-hop to the destination. This flexibility of self-configuring and self-administration makes it lucrative for various applications in military operations, wireless mesh networks, wireless sensor networks etc. The wireless nature of mobile Ad hoc network needs address issues such as efficient and reliable routing [1].

The structure of the paper is as follows. Section II deals with related work. Section III shows the design issues and challenges in MANET. Section IV presents the performance metric in MANET. Section V presents the comparison of basic routing protocols and Section VI concludes the paper.

\section{RELATED WORK}

Exhaustive literature survey is carried on various routing protocols in MANET. Efficient routing methodologies have been proposed satisfying different requirements in MANET. The authors in [3] have analyzed two distinct Dynamic Source Routing (DSR) and Direct-Sequenced Distance Vector Routing (DSDV) protocols. The authors discussed the performance effect on varying the values of the periodic update interval. The results further can help while choosing the values of parameters to be used for DSDV in a real ad hoc network working under certain constraints.

The authors in [4] has discussed about two mobile ad-hoc routing protocols DSDV and AODV where the DSDV is a proactive protocol driven by routing tables which are maintained at each node. The AODV is a reactive protocol where a route is discovered to a destination on demand.

In [5], the authors have discussed the performance of routing protocol and analyzed these protocols based on network load, mobility, and network size. Analysis results verified the DSDV and AODV routing protocol performances.

In [6], authors presented the performance of DSDV protocol for four different mobility models called Random Waypoint, Reference Point Group Mobility, Gauss Markov \& Manhattan Mobility Model with varying network load \& speed and proved that DSDV protocol with RPGM mobility model has optimized results with varying load and speed of network.

The authors in [7] present different routing protocols proposed in literature and also provides a comparison between them. They can be categorized broadly as proactive and reactive and hybrid protocols. A comparative study of Reactive, Proactive and Hybrid routing protocols is given. They have analyzed various issues in routing.

The design issues and challenges due to various unique characteristics of MANET were studied and analyzed in [8]. Further, various to be considered for designing and selection of a routing protocol in ad-hoc network with stressing on changing topology due to mobility of the nodes is discussed.

Findings of literature survey, motivates to design efficient routing protocol with different design issues, characteristics and QoS requirements [9].

\section{ISSUES AND CHALLENGES}

The following section details about issues and challenges based on basic characteristic of MANET.

\section{a. Characteristics of MANET}

The main characteristics of MANET that cause routing protocols to overcome various issues and challenges are listed as follows. 
1. Infrastructure less and no central administration leads to frequent topology change

2. Deal with autonomous terminal that have self organizing ability

3. Handling dynamic topology due to node mobility

4. Wireless links are prone attack

5. No centralized control and No access point required

6. Support Multi hop routing

7. Light-weight terminal with limited battery back up

b. Design issues of routing protocols:

The design issues of routing protocols in MANET are given as follows.

1. Handling nodes mobility

2. Maintenance of route

3. Unpredictable topology change

4. Infrastructure less and self-operated

5. Autonomous

6. Unreliability of wireless medium

7. Difficulty in discovery of devices

8. Limited resources availability.

9. Security towards internal and external attacks

In Ad hoc networks basic routing protocols are dynamic source routing protocol (DSR), destination sequenced distance vector (DSDV) and Ad hoc On Demand Distance Vector (AODV) are analyzed based on performance metric as discussed in next section.

\section{PERFORMANCE METRIC}

The various performances metric to be considered are given as follows [10].

I. Packet Delivery Ratio : The ratio of number of packet sent from source to destination
$P_{d r}=\frac{\text { total packet received at destination }}{\text { total packet sent from source }}$.

Where, $P_{d r}$ : packet delivery ratio

II. Packet Dropped: The count of packets that are not received by the destination

$$
P_{\text {dropped }}=P_{t s}-P_{r c} \times E_{\text {ele }} \times n \ldots
$$

Where, $\mathrm{P}_{\text {dropped }}$ : Packet dropping rate Pts : total packet sent from source Prc : total packet received at destination Eele : dissipated energy by radio to run

III. End To End Delay: The delay experienced by a packet from the time it was sent by a source till the time it was received at the destination

$D=\frac{1}{N} \sum_{i=1}^{s}($ Pri - Psi $)$

Where,

D: end- to-end delay

$\mathrm{N}$ : number of successfully received packets

$\mathrm{Pr}_{\mathrm{i}}$ : packet i received time

$\mathrm{Ps}_{\mathrm{i}}$ : packet i sent time

i : unique packet id

IV. Routing Overhead: The number of control packets produced per mobile node. Control packets include route requests, replies and error messages.

V. Route Length: The average route length given in terms of the number of hops that the all the packets require to reach the destination from the source.

\section{COMPARISON OF BASIC ROUTING PROTOCOLS}

Table 1 shows the comparison of routing protocols in wireless sensor networks.

Table 1. Comparison of basic routing protocols

\begin{tabular}{|c|c|c|c|}
\hline Parameter & DSR & AODV & DSDV \\
\hline Routing Type & Reactive & Reactive & Proactive \\
\hline Route discovery & On -Demand & On-demand & Table- driven \\
\hline Feature & $\begin{array}{l}\text { Has route discovery and route } \\
\text { maintenance }\end{array}$ & Support unicast and multicast & $\begin{array}{lll}\begin{array}{l}\text { Solve } \\
\text { problem }\end{array} & \text { routing } & \text { loop } \\
\end{array}$ \\
\hline Path information & $\begin{array}{l}\text { Routing table not needed, as } \\
\text { route is contained in packet } \\
\text { header }\end{array}$ & $\begin{array}{l}\text { Path set-up done only when } \\
\text { needed }\end{array}$ & $\begin{array}{l}\text { Routing table store path } \\
\text { information and must be } \\
\text { regularly updated. This } \\
\text { consume battery and } \\
\text { bandwidth }\end{array}$ \\
\hline Limitation & $\begin{array}{l}\text { Not scalable to large network. } \\
\text { Intermediate node spend lot of } \\
\text { time to process any control } \\
\text { information }\end{array}$ & $\begin{array}{l}\text { AODV is vulnerable to various } \\
\text { attack as it is based on } \\
\text { cooperation among all nodes }\end{array}$ & $\begin{array}{l}\text { Not available for highly } \\
\text { dynamic networks }\end{array}$ \\
\hline Delay & More than AODV & Less than DSDV & Less \\
\hline Routing overhead & More than AODV & Less than DSDV & Less \\
\hline Packet delivery ratio & Less than AODV & Least & More than AODV \\
\hline
\end{tabular}


Various protocols considered for comparison are DSR, AODV, DSDV routing protocols. These routing protocols can be broadly classified into proactive, reactive and table driven routing protocols. Various performance metrics supported by these routing are listed.

\section{CONCLUSION}

Routing protocols in MANET is an important research area. Efficient design of routing protocol must deal with various issues to be considered for achieving reliable routing with less power consumption and error rates in network. The study presents review the basic routing protocols of wireless ad hoc network technology and the comparative study among these basic routing protocols highlights their applicability to meet the needs of different applications.

\section{REFERENCES}

[1] RajaramAyyasamy and PalaniswamiSubramani, "An Enhanced Distributed Certificate Authority Scheme for Authentication in Mobile Ad-hoc Networks", The International Arab Journal of Information Technology, Vol. 9, No. 3, May 2012

[2] Rajkumar, Banoth, and G. Narsimha. "Trust Based Certificate Revocation for Secure Routing in MANET." Procedia Computer Science 92 (2016): 431-441.

[3] Patil, Abhishek, and Amit S. "Routing protocols for ad-hoc wireless networks." (2001).

[4] Gorantala, Krishna. "Routing protocols in mobile ad-hoc networks." A Master'thesis in computer science, pp-1-36 (2006).
[5] Khandakar, Amith. "Step by Step Procedural Comparison of DSR, AODV and DSDV Routing protocol." International Proceedings of Computer Science \& Information Tech. Vol. 40. No. 12. 2012

[6] Boukerche, Azzedine, Alessandro Fabbri, and Sajal K. Das. "Analysis of randomized congestion control in DSDV routing." Modeling, Analysis and Simulation of Computer and Telecommunication Systems, 2000. Proceedings. 8th International Symposium on. IEEE, 2000.

[7] Varshney, Pankaj Kumar, G. S. Agrawal, and Sudhirkumarsharma. "Energy Consumption Analysis of Wireless Ad hoc Networks Routing Protocols under different energy models." INROADS-An International Journal of Jaipur National University 5.1s (2016): 250-253.

[8] Varshney, Pankaj Kumar, G. S. Agrawal, and Sudhir Kumar Sharma. "Relative performance analysis of proactive routing protocols in Wireless Ad hoc Networks using Varying Node Density." Invertis Journal of Science \& Technology 9.3 (2016): 161-169.

[9] Menon, Varun G., and P. M. Joe Prathap. "Analysing the behaviour and performance of opportunistic routing protocols in highly mobile wireless ad hoc networks." International Journal of Engineering and Technology 8.5 (2016): 19161924.

[10] Dhenakaran, Dr SS, and A. Parvathavarthini. "An overview of Routing protocols in mobile ad-hoc network." International Journal of Advanced Research in Computer Science and Software Engineering 3.2 (2013).

[11] Menon, Varun G., and P. M. Joe Prathap. "Routing in highly dynamic ad hoc networks: Issues and Challenges." International Journal of Computer Science and Engineering 8.4 (2016): 112-116 